\title{
Evaluation of a new arterial pressure-based cardiac output device requiring no external calibration
}

\author{
Christopher Prasser ${ }^{1}$, Sylvia Bele ${ }^{2}$, Cornelius Keyl ${ }^{3}$, Stefan Schweiger ${ }^{1}$, \\ Benedikt Trabold ${ }^{1}$, Matthias Amann ${ }^{1}$, Julia Welnhofer ${ }^{1}$ and \\ Christoph Wiesenack*1
}

\begin{abstract}
Address: ${ }^{1}$ Department of Anesthesiology, University Hospital Regensburg, Franz-Josef-Strauß-Allee 11, Regensburg, 93052, Germany, ${ }^{2}$ Department of Neurosurgery, University Hospital Regensburg, Franz-Josef-Strauß-Allee 11, Regensburg, 93052, Germany and ${ }^{3}$ Department of Anesthesiology, Heart-Center Bad Krozingen, Südring 15, Bad Krozingen, 79189, Germany

Email: Christopher Prasser - christopher.prasser@klinik.uni-regensburg.de; Sylvia Bele - sylvia.bele@klinik.uni-regensburg.de; Cornelius Keyl - cornelius.keyl@herzzentrum.de; Stefan Schweiger - steschweiger@web.de; Benedikt Trabold - benedikt.trabold@klinik.uniregensburg.de; Matthias Amann - matthias.amann@klinik.uni-regensburg.de; Julia Welnhofer - julia.welnhofer@web.de; Christoph Wiesenack* - christoph.wiesenack@klinik.uni-regensburg.de

* Corresponding author
\end{abstract}

Published: 9 November 2007

BMC Anesthesiology 2007, 7:9 doi: 10.1 186/I47/-2253-7-9
Received: 14 April 2007

Accepted: 9 November 2007

This article is available from: http://www.biomedcentral.com//47I-2253/7/9

(C) 2007 Prasser et al; licensee BioMed Central Ltd.

This is an Open Access article distributed under the terms of the Creative Commons Attribution License (http://creativecommons.org/licenses/by/2.0), which permits unrestricted use, distribution, and reproduction in any medium, provided the original work is properly cited.

\begin{abstract}
Background: Several techniques have been discussed as alternatives to the intermittent bolus thermodilution cardiac output $\left(\mathrm{CO}_{\mathrm{PAC}}\right)$ measurement by the pulmonary artery catheter (PAC). However, these techniques usually require a central venous line, an additional catheter, or a special calibration procedure. A new arterial pressure-based cardiac output $\left(\mathrm{CO}_{\mathrm{AP}}\right)$ device (FloTrac ${ }^{\mathrm{TM}}$, Vigileo ${ }^{\mathrm{TM}}$; Edwards Lifesciences, Irvine, CA, USA) only requires access to the radial or femoral artery using a standard arterial catheter and does not need an external calibration. We validated this technique in critically ill patients in the intensive care unit (ICU) using $\mathrm{CO}_{\mathrm{PAC}}$ as the method of reference.

Methods: We studied 20 critically ill patients, aged 16 to 74 years (mean, $55.5 \pm 18.8$ years), who required both arterial and pulmonary artery pressure monitoring. $\mathrm{CO}_{\text {PAC }}$ measurements were performed at least every 4 hours and calculated as the average of 3 measurements, while $\mathrm{CO}_{\mathrm{AP}}$ values were taken immediately at the end of bolus determinations. Accuracy of measurements was assessed by calculating the bias and limits of agreement using the method described by Bland and Altman.

Results: A total of 164 coupled measurements were obtained. Absolute values of $\mathrm{CO}_{\mathrm{PAC}}$ ranged from 2.80 to $10.80 \mathrm{l} / \mathrm{min}$ (mean $5.93 \pm 1.55 \mathrm{l} / \mathrm{min}$ ). The bias and limits of agreement between $\mathrm{CO}_{\mathrm{PAC}}$ and $\mathrm{CO}_{\mathrm{AP}}$ for unequal numbers of replicates was $0.02 \pm 2.92 \mathrm{l} / \mathrm{min}$. The percentage error between $\mathrm{CO}_{\mathrm{PAC}}$ and $\mathrm{CO}_{\mathrm{AP}}$ was $49.3 \%$. The bias between percentage changes in $C \mathrm{O}_{\mathrm{PAC}}\left(\triangle \mathrm{CO} \mathrm{P}_{\mathrm{PAC}}\right)$ and percentage changes in $\mathrm{CO}_{\mathrm{AP}}\left(\Delta C \mathrm{O}_{\mathrm{AP}}\right)$ for consecutive measurements was $-0.70 \% \pm 32.28 \%$. $C O_{P A C}$ and $C_{\text {AP }}$ showed a Pearson correlation coefficient of $0.58(p<$ $0.0 \mathrm{I})$, while the correlation coefficient between $\Delta \mathrm{CO}_{\mathrm{PAC}}$ and $\Delta \mathrm{CO}_{\mathrm{AP}}$ was $0.46(p<0.0 \mathrm{I})$.

Conclusion: Although the $\mathrm{CO}_{\mathrm{AP}}$ algorithm shows a minimal bias with $\mathrm{CO}_{\mathrm{PAC}}$ over a wide range of values in an inhomogeneous group of critically ill patients, the scattering of the data remains relative wide. Therefore, the used algorithm ( $\vee$ I.03) failed to demonstrate an acceptable accuracy in comparison to the clinical standard of cardiac output determination.
\end{abstract}




\section{Background}

Accurate evaluation of cardiac performance is an important goal in the treatment of critically ill patients. Usually a pulmonary artery catheter (PAC) is placed for assessment of cardiac output (CO), but as a result of the current discussion about the usefulness and risks of the PAC $[1,2]$, several less invasive techniques have been discussed as alternatives to the intermittent bolus thermodilution cardiac output $\left(\mathrm{CO}_{\mathrm{PAC}}\right)$ measurement by the PAC [3], which still represents the clinical standard.

Particularly techniques using arterial waveform analysis for CO assessment (PiCCOplus ${ }^{\circledast}$, Pulsion Medical Systems, Munich, Germany and LiDCO ${ }^{\mathrm{TM}}$ plus, LiDCO Ltd, Cambridge, UK) have been tested as alternatives to the PAC, partly with excellent results [4-10]. However, these techniques usually require an additional catheter, a central venous line, or a special calibration procedure such as transpulmonary thermodilution (PiCCOplus ${ }^{\circledR}$ ) or lithium dilution (LiDCO ${ }^{\mathrm{Tm}}$ plus). Furthermore, the inability of these devices to compensate for changes in individual aortic input impedance or central aortic compliance, which both may alter the calculated CO by the pulse contour technique in hemodynamic instability, can lead to erroneous assessment of CO [11,12].

A new arterial pressure-based cardiac output $\left(\mathrm{CO}_{\mathrm{AP}}\right)$ device (FloTrac ${ }^{\mathrm{TM}}$, Vigileo ${ }^{\mathrm{TM}}$; Edwards Lifesciences, Irvine, CA, USA) only requires access to the radial or femoral artery using a standard arterial catheter and does not need an external calibration. To facilitate $\mathrm{CO}_{\mathrm{AP}}$ assessment by arterial pulse waveform analysis without an external calibration mode, the system estimates individual arterial compliance according to Langewouters five component model [13] and continuously compensates for changes in vascular tone by detecting characteristic alterations in the arterial pressure waveform. But until now there has been only limited information about the value of this new device [14-16].

Therefore, this study was performed to evaluate the accuracy of FloTrac ${ }^{\mathrm{TM}}$-derived $\mathrm{CO}_{\mathrm{AP}}$ assessment in an inhomogeneous group of critically ill patients in a neurosurgical intensive care unit (ICU) using $\mathrm{CO}_{\mathrm{PAC}}$ as the method of reference.

\section{Methods}

After obtaining approval of the Institutional Ethics Committee of the University of Regensburg Medical Centre (Regensburg, Germany) and with written informed consent from the patient or their relative, we studied 20 critically ill patients (10 male), aged 16 to 74 years (mean, $55.5 \pm 18.8$ years) in a neurosurgical ICU, who due to the severity of their illness required both, arterial and pulmonary artery pressure monitoring. Patients with intracardiac shunts or peripheral vascular disease were excluded from the study.

Analgesia based sedation was maintained with an infusion of fentanyl of $1.5-4.5 \mathrm{mg} \cdot \mathrm{kg}^{-1} \cdot \mathrm{h}^{-1}$ and midazolam of $0.15-0.35 \mathrm{mg} \cdot \mathrm{kg}^{-1} \cdot \mathrm{h}^{-1}$, supplemented with an infusion of ketamine of $1.5-4.0 \mathrm{mg} \cdot \mathrm{kg}^{-1} \cdot \mathrm{h}^{-1}$ in some patients. Pressure controlled ventilation (BiLevel ${ }^{\oplus}$-mode, Bennett $840^{\mathrm{TM}}$ Ventilator System, Puritan Bennett, Pleasanton, CA, USA) with a positive end expiratory pressure of 5-15 $\mathrm{mmHg}$ and a tidal volume of $6-8 \mathrm{ml} / \mathrm{kg}$ to an end tidal $\mathrm{pCO}_{2}$ of 32-38 mmHg was maintained throughout the study.

All patients received a radial arterial line for continuous monitoring of arterial blood pressure (Siemens monitor SC 9000, Erlangen, Germany). A 7.5F pulmonary artery catheter (Baxter Healthcare Corporation, Irvine, CA, USA) was inserted via an $8.5 \mathrm{~F}$ introducer into the internal jugular or subclavian vein for intermittent thermodilution cardiac output $\left(\mathrm{CO}_{\mathrm{PAC}}\right)$ measurement (Siemens monitor SC 9000, Erlangen, Germany). $\mathrm{CO}_{\mathrm{PAC}}$ measurements were performed at least every 4 hours by injection of $10 \mathrm{ml}$ iced saline solution via the CVP port of the PAC and subsequent detection by the thermistor embedded into the PAC. The average of 3 measurements, all measured within a $15 \%$ range randomly distributed over the respiratory cycle, was calculated according to the Stewart-Hamilton formula. If there was more than $15 \%$ variation between the values, five measurements were performed, the highest and lowest values from CO calculation were excluded, and the remaining three values averaged.

The FloTrac ${ }^{\mathrm{TM}}$ sensor was attached to the existing arterial line and connected to the Vigileo ${ }^{\mathrm{TM}}$ monitor for arterial pressure-based $\mathrm{CO}_{\mathrm{AP}}$ assessment. Following initiation of the Vigileo ${ }^{\mathrm{TM}}$ monitor by entering patient's age, gender, height and weight, the system computes stroke volume (SV) from the patients arterial pressure signal and displays $\mathrm{CO}_{\mathrm{AP}}$ continuously.

The methodology of arterial pressure-based $\mathrm{CO}_{\mathrm{AP}}$ assessment by the FloTrac ${ }^{\mathrm{TM}}$ system has been previously described by Manecke [17] and involves the calculation of SV regarding the proven relationship between pulse pressure $(\mathrm{PP}$, the difference between systolic and diastolic blood pressure) and SV [18,19]. As demonstrated by Boulain, aortic PP is proportional to SV and is inversely related to aortic compliance for a given SV [18]. Based upon this physiological principle, the FloTrac ${ }^{\mathrm{TM}}$ device assesses the arterial pulse waveform at a sampling rate of $100 \mathrm{~Hz}$ over a 20 second period, which generates approximately 2000 data points, and calculates the standard deviation $\left(\mathrm{SD}_{\mathrm{AP}}\right)$ of each measured beat to provide a robust assessment of key PP characteristics. Calculation of 
$\mathrm{SD}_{\mathrm{AP}}$ should be more precisely related to $\mathrm{SV}$, in that multiple values are measured to determine the variability, rather than a simple single PP measurement [20]. $\mathrm{SD}_{\mathrm{AP}}$ of the arterial pressure waveform is computed on a beatto-beat basis using the following equation:

$$
S D_{A P}=\sqrt{\frac{1}{N-1} \sum_{k=0}^{N-1}\left[A P(k)-A P_{\text {mean }}\right]^{2}}
$$

where $\operatorname{AP}(\mathrm{k})$ is the $\mathrm{k}^{\text {th }}$ pulse pressure sample in the current beat, $\mathrm{N}$ is the total number of samples, and $\mathrm{AP}_{\text {mean }}$ is the mean of arterial pressure [21]. To continuously compensate for changes in vascular compliance and peripheral resistance, a scale factor $\chi$ is calculated on the basis of biometric data [13] and the analysis of characteristic alterations of the individual arterial pressure waveform, such as skewness or kurtosis, reflecting changes in vascular tone. In the used version of software (V 1.03), $\chi$ was recalculated every 10 minutes. Thus, $\mathrm{CO}_{\mathrm{AP}}$ is computed as:

$$
C \mathrm{O}_{\mathrm{AP}}=H R \bullet S D_{\mathrm{AP}} \bullet \chi
$$

where HR is the heart rate and $\chi$ a scale factor proportional to vascular compliance and peripheral resistance.

FloTrac ${ }^{\mathrm{TM}}$-derived $\mathrm{CO}_{\mathrm{AP}}$ values were taken immediately at the end of bolus determinations, representing an average over the last minutes. Measurements were completed when the PAC or the arterial catheter was removed, or the patient was weaned from mechanical ventilation.

\section{Statistical Analysis}

The bias between $\mathrm{CO}_{\mathrm{PAC}}$ and $\mathrm{CO}_{\mathrm{AP}}$ for all values and for percentage changes ( $\Delta=$ trend analysis) between consecutive $\mathrm{CO}$ determinations was calculated as the mean difference between measurements and expresses the agreement between methods. To avoid a systematical calculation error in the case of repeated measurements per subject, the bias between methods was calculated according to a modified statistical approach by Bland and Altman for unequal numbers of replicates [22]. The upper and lower limits of agreement (LOA), defining the range in which $95 \%$ of the differences between methods are expected to lie, were calculated as bias $\pm 1.96 \mathrm{SD}$. The bias and the LOA are reported as $95 \%$ confidence interval. The percentage error, defined as the standard deviation of the bias ( \pm $1.96 \mathrm{SD}$ ) divided by the mean $\mathrm{CO}$, was calculated according to Critchley and Critchley [23]. The acceptable limit of variability between techniques was determined as a percentage error below $\pm 30 \%$. Linear regression analysis was performed between the absolute values of $\mathrm{CO}_{\mathrm{PAC}}$ and $\mathrm{CO}_{\mathrm{AP}}$ and between percentage changes in $\mathrm{CO}_{\mathrm{PAC}}$ and $\mathrm{CO}_{\mathrm{AP}}$. A p $<0.05$ was regarded as significant.

\section{Results}

Demographic data, patient characteristics and the number of measurement repetitions per patient are presented in Table 1.

A total of 164 coupled measurements were obtained. Absolute values of $\mathrm{CO}_{\text {PAC }}$ ranged from 2.80 to $10.80 \mathrm{l} / \mathrm{min}$ (mean $5.93 \pm 1.55 \mathrm{l} / \mathrm{min}$ ), while absolute values of $\mathrm{CO}_{\mathrm{AP}}$ ranged from 3.40 to $9.80 \mathrm{l} / \mathrm{min}$ (mean $5.91 \pm 1.15 \mathrm{l} / \mathrm{min}$ ). The modified Bland-Altman analysis for an unequal number of replicates between $\mathrm{CO}_{\mathrm{PAC}}$ and $\mathrm{CO}_{\mathrm{AP}}$ showed a mean bias and LOA of $0.02 \pm 2.92 \mathrm{l} / \mathrm{min}$ (Figure 1A). The percentage error between $\mathrm{CO}_{\mathrm{PAC}}$ and $\mathrm{CO}_{\mathrm{AP}}$ was $49.3 \%$. $\mathrm{CO}_{\mathrm{PAC}}$ and $\mathrm{CO}_{\mathrm{AP}}$ showed a correlation coefficient of 0.58 $(p<0.01)$ as displayed in Figure 1B.

A total of 144 coupled measurements were obtained for a trend analysis of percentage changes in $\mathrm{CO}$. The bias between percentage changes in $\mathrm{CO}_{\mathrm{PAC}}\left(\triangle \mathrm{CO}_{\mathrm{PAC}}\right)$ and percentage changes in $\mathrm{CO}_{\mathrm{AP}}(\triangle \mathrm{CO} \mathrm{AP})$ for consecutive measurements was $-0.70 \%$ with LOA of $\pm 32.28 \%$ (Figure $2 \mathrm{~A}$ ). $\Delta \mathrm{CO}_{\mathrm{PAC}}$ and $\Delta \mathrm{CO}_{\mathrm{AP}}$ revealed a correlation coefficient of $0.46(p<0.01)$ as shown in Figure 2B.

The results of the analysis of agreement, assessed by bias, and the distribution of the observed differences, indicated by bias $\pm 1.96 \mathrm{SD}$ as upper and lower LOA including $95 \%$ confidence intervals are presented in Table 2.

\section{Discussion}

This should be the first investigation evaluating a new arterial pressure-based CO-device in an inhomogeneous group of critically ill patients on a neurosurgical ICU in comparison to the clinical standard of CO determination. The fact that all patients received pulmonary artery pressure monitoring due to the severity of their illness differentiates our trial from previous studies, which all evaluated FloTrac-system in elective cardiac surgical patients, representing a relatively homogeneous, hemodynamically stable and artificial group of patients in which pulmonary artery pressure monitoring is not necessarily performed.

The results of the present study demonstrate a minimal bias between the absolute values of $\mathrm{CO}_{\mathrm{PAC}}$ and $\mathrm{CO}_{\mathrm{AP}}$ over a large range of values in an inhomogeneous group of critically ill patients. However, a relative wide scattering of the data could be observed, possibly due to the calculation mode with which the algorithm compensates for changes in vascular tone.

Several studies have shown that less invasive devices for $\mathrm{CO}$ assessment based on arterial waveform analysis, such as PiCCOplus ${ }^{\circledast}$ or LiDCO ${ }^{\mathrm{Tm}}$ plus, are valuable alternatives to the intermittent thermodilution technique by the 
Table I: Demographic data and patient characteristics

\begin{tabular}{|c|c|c|c|c|c|c|}
\hline Patient & Diagnosis & Age (years) & Sex & Apache II Score & BMI $\left(\mathrm{kg} / \mathrm{m}^{2}\right)$ & Measurements (n) \\
\hline I & $\begin{array}{l}\text { ICB, Acute heart } \\
\text { failure }\end{array}$ & 70 & female & 37 & 34.3 & 20 \\
\hline 2 & $\begin{array}{l}\text { Cerebral infarct, } \\
\text { Angina pectoris }\end{array}$ & 73 & female & 36 & 27.3 & 6 \\
\hline 3 & $\begin{array}{l}\text { Craniocerebral } \\
\text { injury }\end{array}$ & 21 & male & 14 & 27.7 & 5 \\
\hline 4 & $\mathrm{SAH}$ & 46 & female & 12 & 19.6 & 7 \\
\hline 5 & $\begin{array}{l}\text { Craniocerebral } \\
\text { injury, Thorax } \\
\text { trauma }\end{array}$ & 18 & male & 28 & 19.0 & 8 \\
\hline 6 & $\begin{array}{l}\text { SAH, Cerebral } \\
\text { infarct }\end{array}$ & 49 & female & 26 & 25.8 & 8 \\
\hline 7 & Sepsis & 62 & male & 37 & 31.4 & 6 \\
\hline 8 & $\mathrm{SAH}$ & 66 & male & 21 & 28.4 & 15 \\
\hline 9 & $\mathrm{PAH}$ & 71 & female & 17 & 28.6 & 6 \\
\hline 10 & ICB, Hypertension & 49 & female & 21 & 24.5 & 14 \\
\hline 11 & $\begin{array}{l}\text { Craniocerebral } \\
\text { injury, } \\
\text { Cardiopulmonary } \\
\text { resuscitation }\end{array}$ & 16 & female & 31 & 23.9 & 7 \\
\hline 12 & $\begin{array}{l}\text { Coronary heart } \\
\text { disease, CABG }\end{array}$ & 71 & male & 29 & 31.1 & 5 \\
\hline 13 & $\begin{array}{l}\text { Mitral } \\
\text { regurgitation, MVR }\end{array}$ & 74 & male & 37 & 33.0 & 4 \\
\hline 14 & $\mathrm{SAH}, \mathrm{ICB}$ & 43 & female & 23 & 22.8 & 13 \\
\hline 15 & $\begin{array}{l}\text { Coronary heart } \\
\text { disease, Mitral } \\
\text { regurgitation, } \\
\text { CABG, MVR }\end{array}$ & 64 & male & 12 & 22.4 & 3 \\
\hline 16 & $\begin{array}{l}\text { Coronary heart } \\
\text { disease, CABG }\end{array}$ & 69 & male & 20 & 28.3 & 8 \\
\hline 17 & Cerebral infarct & 73 & female & 32 & 35.9 & 7 \\
\hline 18 & $\begin{array}{l}\text { SAH, Pulmonary } \\
\text { edema }\end{array}$ & 53 & male & 27 & 26.4 & 8 \\
\hline 19 & $\begin{array}{l}\text { Intracranial } \\
\text { haematoma }\end{array}$ & 70 & male & 20 & 33.1 & 11 \\
\hline 20 & $\begin{array}{l}\text { Sepsis, } \\
\text { Cardiopulmonary } \\
\text { resuscitation }\end{array}$ & 52 & female & 34 & 24.2 & 3 \\
\hline all & & $55.5 \pm 18.9$ & 10 male & $25.7 \pm 8.4$ & $27.4 \pm 4.7$ & 164 \\
\hline
\end{tabular}

Data are presented as mean \pm SD or as frequency distributions $(n)$ and simple percentages (\%).

Appreviations: $\mathrm{BMI}=$ body mass index; $\mathrm{CABG}=$ coronary artery bypass grafting; $\mathrm{ICB}=$ intracerebral bleeding; $\mathrm{MVR}=$ mitral valve replacement;

$\mathrm{PAH}=$ pulmonary arterial hypertension; $\mathrm{SAH}=$ subarachnoidal haemorrhage.

PAC [4-10]. However, all these techniques require an additional catheter, a central venous line, or an external calibration procedure. Furthermore, the inability of these techniques to continuously compensate for changes in vascular tone during hemodynamic instability [12] with the consequential need of frequent recalibrations invalidates strictly speaking the claim of a continuously measuring device. Therefore, finding a minimal invasive device for accurate and continuous CO assessment, which is simple to handle and independent of an additional catheter and an external calibration mode, is still of constant clinical interest.
The recently introduced FloTrac ${ }^{\mathrm{TM}}$ system should be an interesting alternative for $\mathrm{CO}$ assessment and may have potential advantages due to its relative non-invasiveness and simplicity, but until now there has been only limited information about the value of this new device [14-16]. Opdam and colleagues recently studied six patients after elective cardiac surgery and stated that the cardiac index (CI) values obtained with the FloTrac ${ }^{\mathrm{TM}}$ system were imprecise compared with the PAC because of an inconsistent bias $\left(0.21 \mathrm{l} \cdot \mathrm{min}^{-1} \cdot \mathrm{m}^{2}\right)$ and a wide scattering of data $\left( \pm 1.02 \mathrm{l} \cdot \mathrm{min}^{-1} \cdot \mathrm{m}^{2}\right)[15]$. However, major limitations of that study were the small number of patients included 

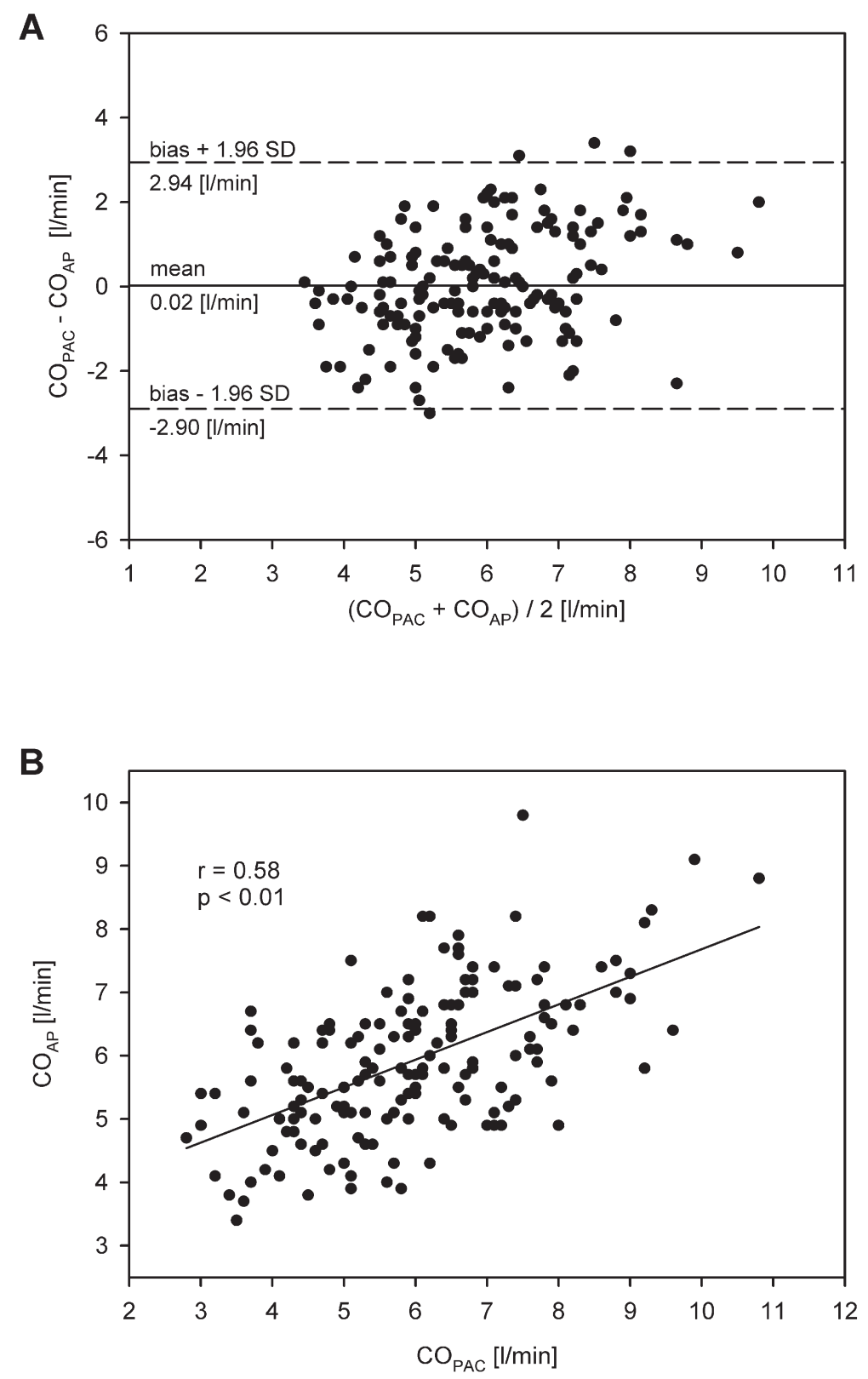

Figure I

Bland-Altman plot (A) and regression analysis (B) for comparison between the intermittent thermodilution-derived cardiac output $\left(\mathrm{CO}_{\mathrm{PAC}}\right)$ by the pulmonary artery catheter $(\mathrm{PAC})$ and the arterial pressure-based cardiac output $\left(\mathrm{CO}_{\mathrm{AP}}\right)$ by the FloTrac ${ }^{\mathrm{TM}}$ system for unequal numbers of replicates. The solid line represents the mean difference (bias) and the dashed lines represent the limits of agreement (bias \pm I.96 SD). 

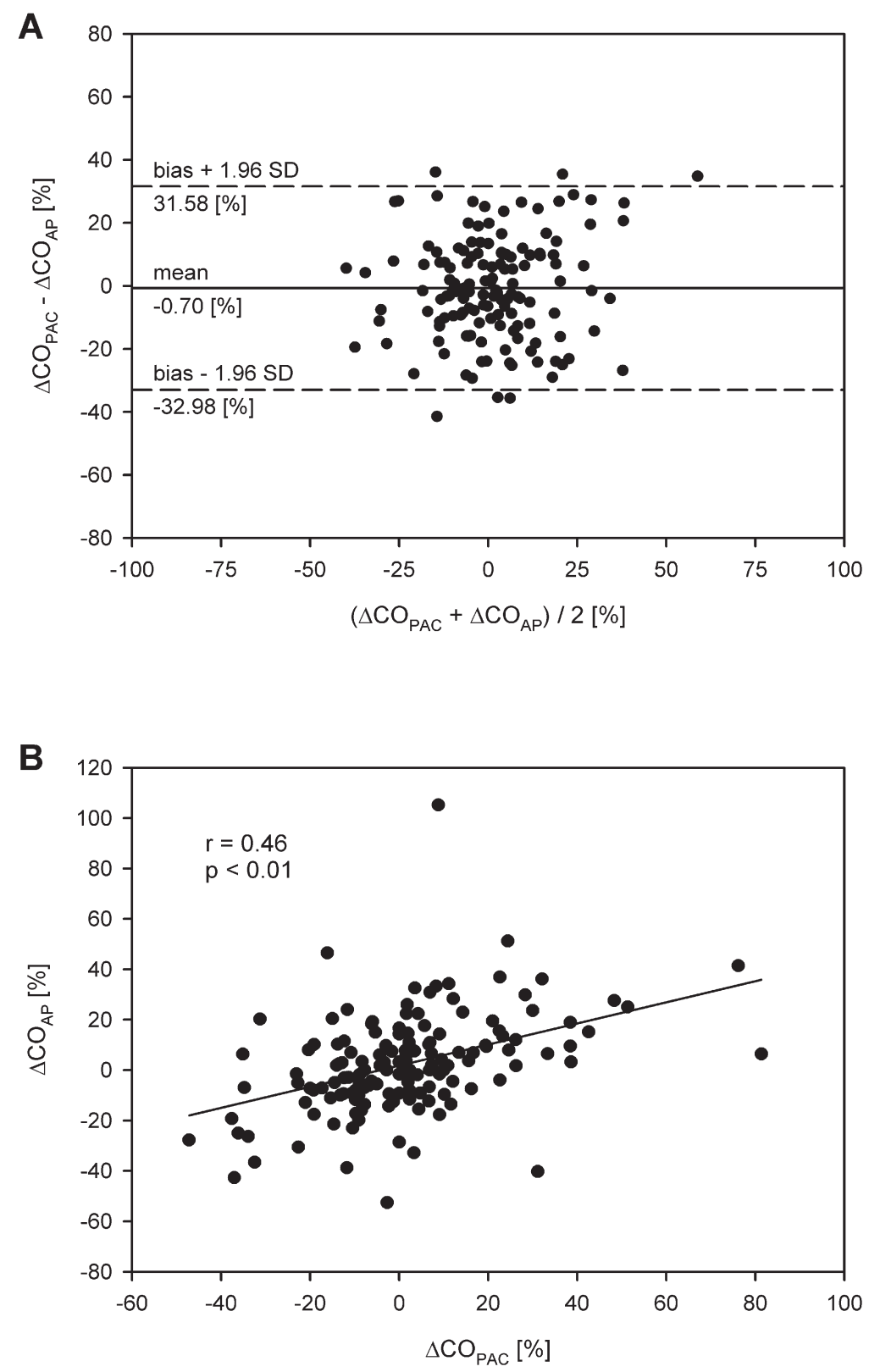

Figure 2

Bland-Altman plot (A) and regression analysis (B) for comparison between the percentage changes in intermittent thermodilution-derived cardiac output $\left(\triangle C \mathrm{O}_{\mathrm{PAC}}\right)$ by the pulmonary artery catheter (PAC) and arterial pressure-based cardiac output $\left(\Delta \mathrm{CO}_{\mathrm{AP}}\right)$ by the FloTrac ${ }^{\mathrm{TM}}$ system for consecutive measurements. The solid line represents the mean difference (bias) and the dashed lines represent the limits of agreement (bias \pm I.96 SD). 
Table 2: Mean difference (bias) between intermittent thermodilution cardiac output $\left(\mathrm{CO}_{\mathrm{PAC}}\right)$ and arterial pressure-based cardiac output $\left(\mathrm{CO}_{\mathrm{AP}}\right)$ for all values $(\mathrm{A})$ and for percentage changes between consecutive measurements of $\mathrm{CO}_{\mathrm{PAC}}\left(\Delta C \mathrm{CO}_{\mathrm{PAC}}\right)$ and $\mathrm{CO} \mathrm{O}_{\mathrm{AP}}$ $\left(\triangle C O_{A P}\right)(B)$ according to the modified approach by Bland and Altman for unequal numbers of replicates with upper and lower limits of agreement (bias \pm I.96 SD), together with $95 \%$ confidence intervals (in parentheses)

\begin{tabular}{|c|c|c|c|c|c|}
\hline $\mathbf{A}$ & $\mathrm{CO}_{\mathrm{PAC}}[1 / \mathrm{min}]$ & $\mathrm{CO}_{\mathrm{AP}}[\mathrm{l} / \mathrm{min}]$ & Bias $(95 \% \mathrm{Cl})[1 / \mathrm{min}]$ & $\begin{array}{c}\text { Upper limit of } \\
\text { agreement }(95 \% \mathrm{Cl})[\mathrm{l} / \\
\mathrm{min}]\end{array}$ & $\begin{array}{c}\text { Lower limit of } \\
\text { agreement }(95 \% \mathrm{Cl}) \\
{[1 / \mathrm{min}]}\end{array}$ \\
\hline & $5.93 \pm 1.55$ & $5.91 \pm 1.15$ & $0.02(-0.40$ to 0.44$)$ & 2.94 (I.8I to 4.07$)$ & $-2.90(-1.77$ to 4.03$)$ \\
\hline \multirow[t]{2}{*}{ B } & $\Delta \mathrm{CO}_{\mathrm{PAC}}[\%]$ & $\Delta \mathrm{CO}_{\mathrm{AP}}[\%]$ & Bias $(95 \% \mathrm{Cl})[\%]$ & $\begin{array}{c}\text { Upper limit of } \\
\text { agreement }(95 \% \mathrm{Cl}) \\
{[\%]}\end{array}$ & $\begin{array}{c}\text { Lower limit of } \\
\text { agreement }(95 \% \mathrm{Cl}) \\
{[\%]}\end{array}$ \\
\hline & $0.91 \pm 18.84$ & $1.61 \pm 17.08$ & $-0.70(-3.45$ to 2.05$)$ & 31.58 (26.85 to 36.30$)$ & $\begin{array}{c}-32.98(-37.70 \text { to } \\
-28.26)\end{array}$ \\
\hline
\end{tabular}

(6 patients), the extremely varying replicates of $\mathrm{CO}$ determinations obtained for each patient ( 8 vs. 158) and an inadequate statistical method. Not using the modified statistical approach by Bland and Altman for unequal numbers of replicates in comparison studies may falsify any result in an unpredictable manner. Variability of measurements made on different subjects is usually much greater than the variability between measurements on the same subject, and this phenomenon should be taken into account. In the worst case the findings may merely reflect the results of the patient with the majority of measuring repetitions.

Sander and co-workers compared 30 CABG patients at four different time points and demonstrated that $\mathrm{CO}$ measurements by the FloTrac ${ }^{\mathrm{TM}}$ system showed a high bias (0.6 $\mathrm{l} / \mathrm{min}$, with a percentage error of $54 \%$ ) and a wide range of $\mathrm{LOA}( \pm 2.8 \mathrm{l} / \mathrm{min})$ in comparison with the $\mathrm{CO}_{\mathrm{PAC}}$ measurement [16]. The authors suggest that $\mathrm{CO}$ assessment with pulse contour analysis techniques in a setting after cardiac surgery basically might not be the ideal method. Similar results were recently reported by Mayer et al, who found a bias and LOA of $0.46 \pm 1.15 \mathrm{l} \cdot \mathrm{min}^{-1} \cdot \mathrm{m}^{2}$ with a percentage error of $46 \%$ for CI comparisons between methods in 40 cardiac surgical patients [14].

Our results are in accordance with the findings of the very limited number of publications regarding the accuracy of $\mathrm{CO}_{\mathrm{AP}}$ assessment and also revealed a relative wide scattering of data as shown in Figure 1A. All these investigations were performed with the same version of FloTrac ${ }^{\mathrm{TM}}$ system software (V 1.03) in which the algorithm compensates for changes in vascular resistance using a 10 minute moving average. Obviously, this method may have difficulty responding to rapid changes in vascular tone during hemodynamic instability. Improvement regarding the response time to changes in vascular tone has been accomplished in a subsequent version of software (V 1.07). The 10 minute moving window for assessing vascular tone was set to a 1 minute moving window.

The estimation of $\mathrm{CO}_{\text {PAC }}$ has become the clinical standard, despite the fact that the method has limited accuracy and may be affected by many factors such as ventilation, volume and temperature of injectate, and technique of indicator injection $[24,25]$, which may have contributed to the variations found between methods in the present study. Differences of at least $15 \%$ in $\mathrm{CO}_{\mathrm{PAC}}$ must be achieved under clinical conditions for clinical relevance when using the triplicate method $[24,26]$. Critchley and Critchley demonstrated that errors of both test and reference method should be combined when assessing comparative $\mathrm{CO}$, which results in a percentage error of $\pm 30 \%$ to be clinically acceptable [23]. The percentage error of \pm $49.3 \%$ between $\mathrm{CO}_{\mathrm{PAC}}$ and $\mathrm{CO}_{\mathrm{AP}}$ found in the present study exceeded the recommended limit to accept a new technique that has been compared to the reference method.

Accuracy of CO assessment is an important issue and should certainly be comparable between methods, but the more relevant question for a clinician, operating with the FloTrac ${ }^{\mathrm{TM}}$ system in an ICU setting, concerns the value of $\mathrm{CO}_{\mathrm{AP}}$ assessment to reasonably detect the direction of changes in $\mathrm{CO}$ under different hemodynamic conditions. Trend analysis of percentage changes in $\mathrm{CO}$ between consecutive measurements (Figure $2 \mathrm{~A}$ ) demonstrates a minimal bias between $\triangle \mathrm{CO}_{\mathrm{PAC}}$ and $\triangle \mathrm{CO}_{\mathrm{AP}}$ and LOA slightly above the value suggested by Critchley and Critchley [23]. While the absolute values of $\mathrm{CO}$ did not show an exact agreement between methods, the direction of changes in $\mathrm{CO}_{\text {PAC }}$ assessment was obviously identified more precisely by the FloTrac ${ }^{\mathrm{TM}}$ system. However, to demonstrate that the $\mathrm{CO}_{\mathrm{AP}}$ algorithm correctly identifies changes in vascular 
tone, interventional studies are required in which the FloTrac ${ }^{\mathrm{TM}}$ system has to be compared to a continuous measuring gold standard.

The range of cardiac outputs in the present investigation is large, which should add power to our findings as all often comparable studies were performed on hypodynamic groups of patients. However, analysing the Bland-Altman plot (Figure 1A), a slight trend for the FloTrac ${ }^{\mathrm{TM}}$ system to underestimate high $\mathrm{CO}$ values and to overestimate low $\mathrm{CO}$ values could be observed. This should be taken into account for further improvements of the algorithm.

Even though the FloTrac ${ }^{\mathrm{Tm}}$ system was designed as a screening tool in a segment of patients, who might have been under-monitored before, any new CO device has to be compared to the clinical gold standard of CO determination by the PAC in varying clinical situations before it could be recommended for a broader application. Once attached to a pre-existing arterial line, the device provides additional information within 20 seconds without any external calibration procedure, which may be valuable in the care of an endangered patient. The advantages of the device compared to other monitoring systems using the arterial pressure for $\mathrm{CO}$ assessment are rationalized by its simplicity and its lack of necessity for a time-consuming placement of an additional catheter.

\section{Limitations}

The results of the present study are limited by the small and varying number of $\mathrm{CO}$ estimations obtained for each patient. However, even in this small group of patients, the findings clearly demonstrate the limitations of the new device and the need for improvements regarding the response time to rapid changes in vascular tone. Furthermore, as changes in vascular tone have not been induced in this investigation, additional interventional studies are required to compare the latest version of FloTrac ${ }^{\mathrm{TM}}$ software to a continuous measuring gold standard regarding its ability to correctly identify changes in arterial compliance.

\section{Conclusion}

FloTrac ${ }^{\mathrm{TM}}$ system has the potential to be a promising alternative for cardiac output measurement, but the used algorithm (V 1.03) failed to demonstrate an acceptable accuracy in comparison to the clinical standard of CO determination. Further studies are required to evaluate the accuracy of this new device in various experimental and clinical settings using the latest version of software.

\section{List of abbreviations}

$\mathrm{AP}=$ arterial pressure; $\mathrm{BMI}=$ body mass index; $\mathrm{CABG}=$ coronary artery bypass grafting; $\mathrm{CO}=$ cardiac output; $\mathrm{CO}_{\mathrm{AP}}=$ arterial pressure-based cardiac output; $\mathrm{CO}_{\mathrm{PAC}}=$ intermittent bolus thermodilution cardiac output; $\mathrm{CVP}=$ central venous pressure; $\mathrm{HR}=$ heart rate; $\mathrm{ICB}=$ intracerebral bleeding; ICU = intensive care unit; $\mathrm{LOA}=$ limits of agreement; $\mathrm{MVR}=$ mitral valve replacement; $\mathrm{PAC}=$ pulmonary artery catheter; $\mathrm{PAH}=$ pulmonary arterial hypertension; $\mathrm{PP}=$ puls pressure; $\mathrm{s}=$ seconds; $\mathrm{SAH}=$ subarachnoid haemorrhage; $\mathrm{SD}=$ standard deviation; $\mathrm{SD}_{\mathrm{AP}}=$ standard deviation of the arterial pressure; $\mathrm{SV}=$ stroke volume; $\chi=$ scale factor proportional to vascular compliance and peripheral resistance.

\section{Competing interests}

CW received a travel grant from Edwards Lifesciences (Irvine, USA) to present this data at an international meeting. The authors declare that there are no further competing interests.

\section{Authors' contributions}

CP designed the study and performed the statistical analysis.

SB collected the clinical data and participated in the design of the study.

CK extensively revised the manuscript.

SS collected the clinical data and participated in the analysis of the data.

BT collected and processed the clinical data.

MA collected the clinical data and participated in the analysis of the data.

JW collected the clinical data and participated in the analysis of the data.

CW designed the study, processed the data and wrote the manuscript.

All author(s) read and approved the final manuscript.

\section{Acknowledgements}

This study was supported in part by a research grant from Edwards Lifesciences, Irvine, CA, USA.

\section{References}

I. Connors AF Jr, Speroff T, Dawson NV, Thomas C, Harrell FE Jr, Wagner D, Desbiens N, Goldman L, Wu AW, Califf RM, Fulkerson WJ Jr, Vidaillet $H$, Broste S, Bellamy P, Lynn J, Knaus WA: The effectiveness of right heart catheterization in the initial care of critically ill patients. JAMA 1996, 276:889-897.

2. Sandham JD, Hull RD, Brant RF, Knox L, Pineo GF, Doig CJ, Laporta DP, Viner S, Passerini L, Devitt H, Kirby A, Jacka M, Canadian Critical Care Clinical Trials Group: A randomized, controlled trial of the use of pulmonary-artery catheters in high-risk surgical patients. N Engl J Med 2003, 348:5-I4.

3. Cholley BP, Payen D: Noninvasive techniques for measurements of cardiac output. Curr Opin Crit Care 2005, I I:424-429. 
4. Bein B, Worthmann F, Tonner PH, Paris A, Steinfath M, Hedderich J, Scholz J: Comparison of esophageal Doppler, pulse contour analysis, and real-time pulmonary artery thermodilution for the continuous measurement of cardiac output. J Cardiothorac Vasc Anesth 2004, 18:185-189.

5. Della Rocca G, Costa MG, Coccia C, Pompei L, Di Marco P, Vilardi V, Pietropaoli P: Cardiac output monitoring: aortic transpulmonary thermodilution and pulse contour analysis agree with standard thermodilution methods in patients undergoing lung transplantation. Can J Anaesth 2003, 50:707-7 I I.

6. Felbinger TW, Reuter DA, Eltzschig HK, Moerstedt K, Goedje O, Goetz AE: Comparison of pulmonary arterial thermodilution and arterial pulse contour analysis: evaluation of a new algorithm. J Clin Anesth 2002, I 4:296-30I.

7. Hamilton TT, Huber LM, Jessen ME: PulseCO: a less-invasive method to monitor cardiac output from arterial pressure after cardiac surgery. Ann Thorac Surg 2002, 74: |408-|4|2.

8. Jonas MM, Tanser SJ: Lithium dilution measurement of cardiac output and arterial pulse waveform analysis: an indicator dilution calibrated beat-by-beat system for continuous estimation of cardiac output. Curr Opin Crit Care 2002, 8:257-26I.

9. Pittman J, Bar Yosef S, SumPing J, Sherwood M, Mark J: Continuous cardiac output monitoring with pulse contour analysis: A comparison with lithium indicator dilution cardiac output measurement. Crit Care Med 2005, 33:2015-202I.

10. Rauch H, Muller M, Fleischer F, Bauer H, Martin E, Bottiger BW: Pulse contour analysis versus thermodilution in cardiac surgery patients. Acta Anaesthesiol Scand 2002, 46:424-429.

II. Rödig G, Prasser C, Keyl C, Liebold A, Hobbhahn J: Continuous cardiac output measurement: pulse contour analysis vs thermodilution technique in cardiac surgical patients. $\mathrm{Br} J$ Anaesth 1999, 82:525-530.

12. Wiesenack C, Fiegl C, Keyser A, Prasser C, Keyl C: Assessment of fluid responsiveness in mechanically ventilated cardiac surgical patients. Eur J Anaesth 2005, 22:658-665.

13. Langewouters GJ, Wesseling KH, Goedhard WJ: The pressure dependent dynamic elasticity of 35 thoracic and 16 abdominal human aortas in vitro described by a five component model. J Biomech 1985, 1 8:613-620.

14. Mayer J, Boldt J, Schöllhorn T, Röhm KD, Mengistu AM, Suttner S: Semi-invasive monitoring of cardiac output by a new device using arterial pressure waveform analysis: a comparison with intermittent pulmonary artery thermodilution in patients undergoing cardiac surgery. $\mathrm{Br} J$ Anaesth 2007, 98: $176-182$.

15. Opdam HI, Wan L, Bellomo R: A pilot assessment of the FloTrac $^{\mathrm{TM}}$ cardiac output monitoring system. Intensive Care Med in press. 2006 Oct 25

16. Sander M, Spies CD, Grubitzsch H, Foer A, Müller M, von Heymann $C$ : Comparison of uncalibrated arterial waveform analysis in cardiac surgery patients with thermodilution cardiac output measurements. Crit Care 2006, I0:RI64.

17. Manecke GR: Edwards FloTrac ${ }^{\mathrm{TM}}$ sensor and Vigileo ${ }^{\mathrm{TM}}$ monitor: easy, accurate, reliable cardiac output assessment using the arterial pulse wave. Expert Rev Med Devices 2005, 2:523-527.

18. Boulain T, Achard J-M, Teboul J-L, Richard C, Perrotin D, Ginies G: Changes in BP induced by passive leg raising predict response to fluid loading in critically ill patients. Chest 2002, I 2 I: | $245-1252$

19. Guyton AC, Hall JE: Vascular distensibility and functions of the arterial and venous systems. In Textbook of medical physiology Edited by: Guyton AC, Hall JE. Philadelphia: Saunders; 2000:I52-I6I.

20. Headley JM: Arterial pressure-based technologies: a new trend in cardiac output monitoring. Crit Care Nurs Clin N Am 2006, I 8: I79-187.

2I. Cecconi M, Wilson J, Rhodes A: Pulse Pressure Analysis. In I Yearbook of intensive care and emergency medicine Edited by: Vincent JL. Berlin, Heidelberg, New York: Springer; 2006:I76-183.

22. Bland JM, Altman DG: Measuring agreement in method comparison studies. Stat Methods Med Res 1999, 8:135-160.

23. Critchley LA, Critchley JA: A meta-analysis of studies using bias and precision statistics to compare cardiac output measurement techniques. J Clin Monit Comput 1999, I5:85-9I.

24. Taylor $\mathrm{SH}$, Silke B: Is the measurement of cardiac output useful in the clinical practice? Br J Anaesth 1988, 60:90-98.
25. Nishikawa T, Dohi S: Errors in the measurement of cardiac output by thermodilution. Can J Anaesth 1993, 40:142-153.

26. Stetz CW, Miller RG, Kelly GE, Raffin TA: Reliability of the thermodilution method in the determination of cardiac output in clinical practice. Am Rev Resp Dis 1982, I 26:1001-1004.

\section{Pre-publication history}

The pre-publication history for this paper can be accessed here:

http://www.biomedcentral.com/1471-2253/7/9/prepub

Publish with Bio Med Central and every scientist can read your work free of charge

"BioMed Central will be the most significant development for disseminating the results of biomedical research in our lifetime. " Sir Paul Nurse, Cancer Research UK

Your research papers will be:

- available free of charge to the entire biomedical community

- peer reviewed and published immediately upon acceptance

- cited in PubMed and archived on PubMed Central

- yours - you keep the copyright
BiolMedcentral 